\title{
The Lexicographical Experiments of Korais and Gazis
}

\section{Kristýna Knapková}

\begin{abstract}
The Greek Enlightenment, within the sphere of language, saw the first efforts to create a comprehensive Greek dictionary. This paper deals with Adamantios Korais, one of the most significant Greek scholars of that time, and his endeavours and ideas regarding the renewed lexicon. It also describes and compares a different approach to working on Greek vocabulary in the heyday of the national revival, represented by another eminent intellectual, Anthimos Gazis. The paper notes their individual principal motives, important predecessors, and particular intentions in creating dictionary, and provides a few examples of specific entries viewed differently by these two representatives of the Enlightenment. The approaches of the two scholars differ in their depth and utility; and the more linguistic versus the rather technically specialized contribution to the lexicography task of each will be outlined and confronted.
\end{abstract}

\section{Keywords}

Korais; Gazis; modern Greek dictionaries; modern Greek lexicography 


\section{Introduction}

Starting briefly with the bibliography, many publications have dealt with Korais's lifework. In comparison, his contemporary Gazis seems somewhat forgotten by modern

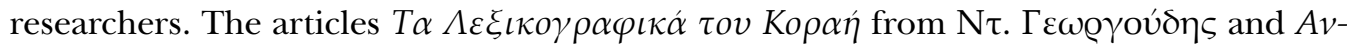

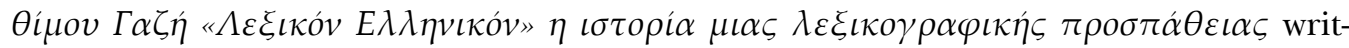

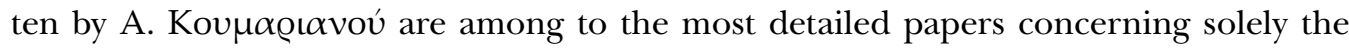
works of these scholars on Greek vocabulary. To the best of my knowledge, there has not yet been a study drawing a comparison between those two intellectuals, even though they were engaged at the same time in very similar scientific activities, and the material related to the Greek Enlightenment is very comprehensive.

Adamantios Korais, one of the most well-known Greek scholars of the European Enlightenment, who settled in Paris, has been generally recognized for his works and ideas on contemporary Greek society, politics, and language. Anthimos Gazis, a less famous but still significant personality connected with the Greek national revival, who settled in Vienna, was Korais's co-worker at $\Lambda o ́ \gamma \iota \varsigma \varsigma E \rho \mu \eta \dot{s}$, the first Greek philological periodical. Prior to the emergence of the Greek national revolution, both of them had - in the pursuit of reviving the Greek language after a long period of non-cultivation - put their efforts into the field of Modern Greek lexicography, because in order to shape the desired form of the new 'proper' Greek language, it was necessary to create not only a grammar but also a good dictionary.

\section{Inspiration}

A few important lexicographical sources served as inspiration for Korais and Gazis, and perhaps for some other scholars at that time. Korais, especially in his later work ( $\Gamma \varepsilon-$

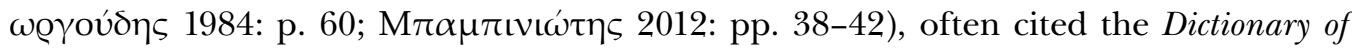
the French Academy, which had been published since 1694, as an example of a valuable, precious lexicon. ${ }^{1}$ Although this dictionary was surely a legitimate model to follow, it is amusing from today's point of view how Korais appraised the French language. As he considered Latin to be a dialect of Greek, he praised French as the European language

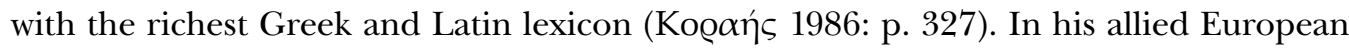
country, he found the first endeavours to create a modern dictionary. In addition to French efforts at dictionary work, he also exalted the attempts of other 'enlightened nations'. Specifically, he kept an interesting correspondence with the German philologist J. G. Schneider, the author of a comprehensive and republished Greek-German

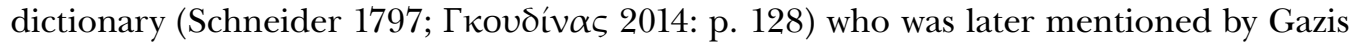
in the introduction to his dictionary. Gazis primarily valued Schneider's lexicographical

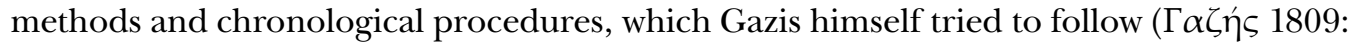

1 Le Dictionnaire de l'Académie françoise dedié au Roy. (1694). (1 ${ }^{\text {re }}$ éd.). Paris: Jean Baptiste Coignard. 
p. viii). The second edition of Schneider's dictionary actually sparked the hesitant Gazis

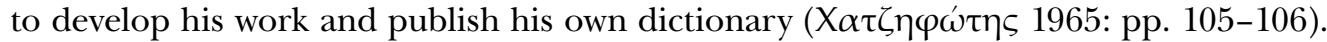

\section{The first lexicographical efforts}

As mentioned above, Korais felt that in order to reshape the desired form of the new 'proper' Greek language, it was necessary to create the grammar that was missing and a good dictionary, a project which his friend Gazis began to work on. Although Korais's workload prevented him from offering significant help to the other scholar, he sent his

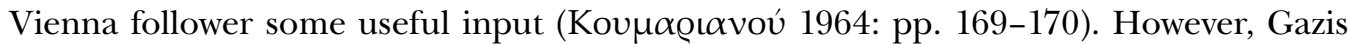
was very excited about his lexicographical task and acted somewhat hastily in his desire for the fastest possible distribution of the dictionary, a fact which was reflected in the outcome.

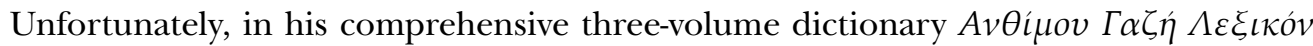

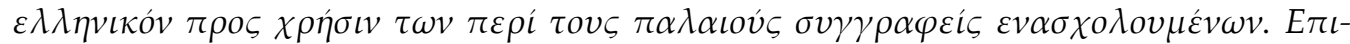

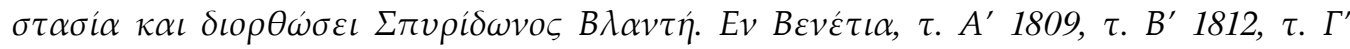
1816 , which was republished repeatedly due to great interest caused by the revolutionary period, Gazis made many mistakes and introduced inaccuracies in the translation

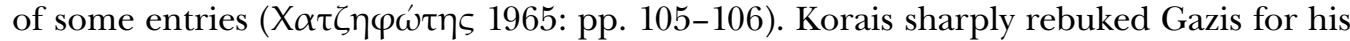
ignorance of German and also because Gazis unthinkingly replicated all of Schneider's

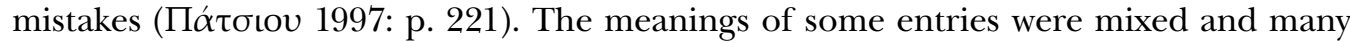
translations had completely incorrect interpretations. Although there were some positive reactions among a few European philhellenes (X $\alpha \tau \zeta \eta \varphi \omega ́ \tau\rceil \varsigma$ 1965: pp. 104-107), Korais was dissatisfied with Gazis's work from the publication of the dictionary's very first

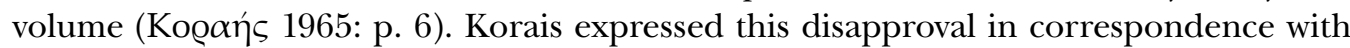
his friend A. Vasileu. Before he looked through the first volume of Gazis's dictionary, he

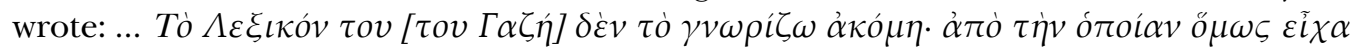

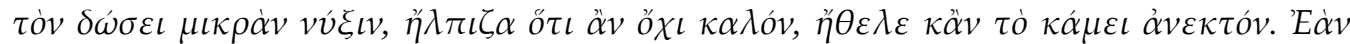

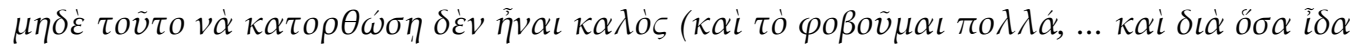

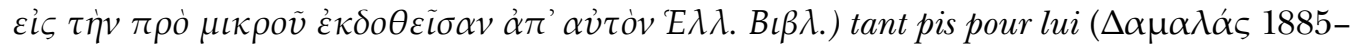
1886: p. 52). ${ }^{2}$ After acquainting himself with the first volume, he expressed his criticism

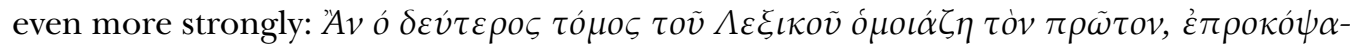

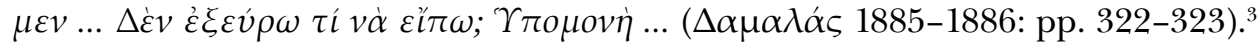

In terms of purely lexicographical efforts, on which Gazis consulted with leading Viennese and Parisian intellectuals (X $\alpha \tau \zeta \eta \varphi \omega \tau \eta \varsigma ~ 1965:$ p. 103), Gazis focused primarily on the formation of new Greek vocabulary in the field of natural sciences. He tried to defend himself against critics with a serious argument about the difficulty of creating, for

2 'I do not yet know his dictionary. I took just a quick look and I had hoped he would try to make it bearable - if not good. He did not manage even that and I am afraid from what I have seen - from what was published - it is too bad for him.' (Author's translation).

3 'If the second edition is similar to the first, we have failed... I don't know what to say. Patience...' (Author's translation). 
instance, medical terminology at a time before the founding of the first Greek scientific institutions (for example, the University of Athens), which could have provided him with

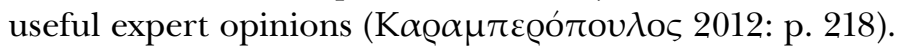

On the other hand, the dictionary Korais desired should have captured everything from antiquity to contemporary written Greek, even though the language was, according to him, for some time devalued with inappropriate words and phrases. Despite these deficiencies, the Greek language, in Korais's opinion, managed to preserve a wide range of correct and melodious expressions (Droulia 2001: p. 256) that had not yet been re-

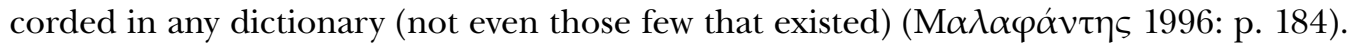

However, Korais's linguistic theory was never able to define clear rules or procedures,

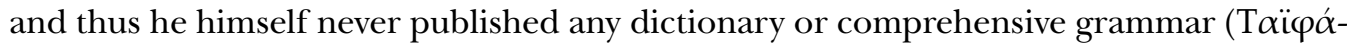
Kov 1998: p. 27). Especially in his prefaces to the works of ancient Greek authors (drawn up between 1804 and 1814), which Korais dedicated to ideas about the state, the church, politics, and not least language, he tried to analyse a few chosen words and this analysis suggested his exemplary dictionary. Nevertheless, he did not approach individual entries entirely uniformly. Some words had only briefly outlined definitions, with a suitable synonym mentioned in some cases, while others were elaborated in detail with their widest objective or metaphorical meanings. Even in terms of content, the suitability or futility of some entries is debatable. While some basic words in Korais's considerations

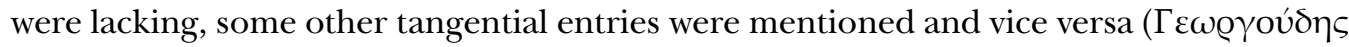
1984: pp. 59-69).

In the post-revolutionary period, a publication of Korais's extensive work, collectively known as A $A \alpha \kappa \tau \alpha$ (1828-1835), contained various comments and dialogues and a multivolume lexicon. According to some scholars, this was actually the first explanatory and etymological dictionary of Modern Greek and therefore the very beginning of Modern

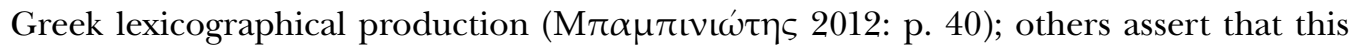

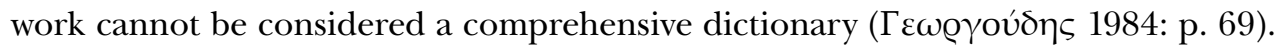

\section{Demonstration and comparison of the efforts}

\section{Nouns, adjectives, and verbs}

As the first noun in the proposed dictionary, Korais chose o o d $v \theta \rho \omega \pi \sigma \varsigma$ ('man, human'). He described its primary and metaphorical meanings with a few examples. He had looked at previously published dictionaries, and he mentioned the word's use by clas-

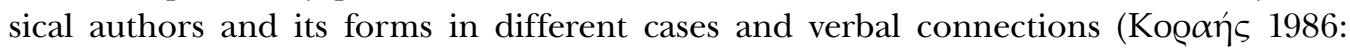
pp. 330-333). Although it is perhaps one of the most important nouns in the basic Greek vocabulary, Korais did not give it as much of his attention as some other words. Gazis, on the other hand, devoted more space to this noun, mentioning several possible combinations in various parts of speech based on one common word basis. Gazis, unlike Korais but like Schneider, connected this entry with the collective nouns $\tau \alpha \dot{\varepsilon} \theta v \eta$ and $\tau \alpha$

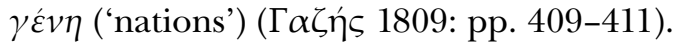


Korais devoted a relatively large space to the noun $\delta$ ( $\tau o ́)$ Bios ('life'). In addition to some set phrases and forms of derived adjectives, he also mentioned the specifics of this substantive's gender diversity. Apart from its primary meaning 'life', he offered the additional interpretation of 'property, tangible good' (or even 'treasure') as a synonym for tó

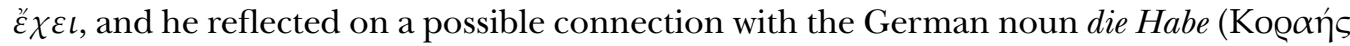
1986: pp. 458-465). Although Gazis attributed several meanings to this noun, there was no space for consideration of this type of comparison in his dictionary. Furthermore, unlike Korais, he introduced the similar word $\delta \beta \iota o ́ \varsigma$ (just as Schneider had), which differs

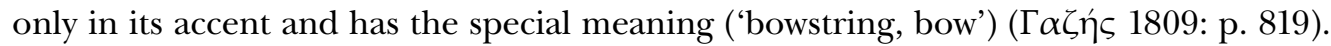

Since Korais's planned dictionary often included adjectives in the analysis of nouns, the selection of adjectives remained somewhat limited. For example, the analysis of $\dot{\alpha} \rho$ -

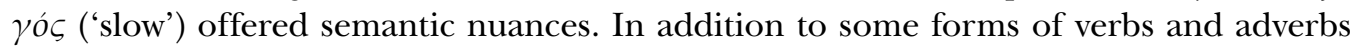
that can be derived from this adjective, Korais mentioned at this point the conceptually similar entry $\beta \rho \alpha \delta i \varsigma$ belonging to a different declination group. He dealt with the com-

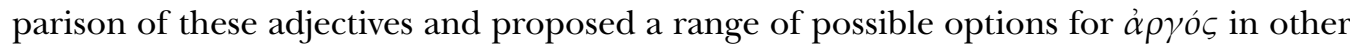

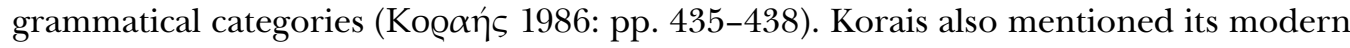

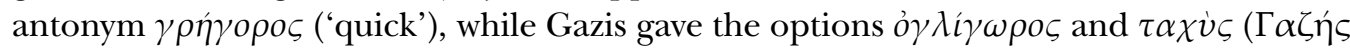
1809: pp. 616-617).

With verbs, Korais made interesting remarks in the first entry $\alpha \gamma \alpha \pi \tilde{\omega}$ ('love'). $\mathrm{He}$ presented the word together with many synonyms and highlighted the incorrect use of certain related forms. For example, he corrected the false $\alpha \gamma \alpha \tau \eta \tau \iota \kappa \eta$ into the proper ả $\gamma \alpha \pi \eta \tau \eta \dot{~(' d e a r ') . ~(K o @ \alpha \eta ́ s ~ 1986: ~ p p . ~ 413-414) . ~ I n ~ c o n t r a s t, ~ G a z i s ~ k e p t ~ b o t h ~ f o r m s ~ o f ~}$ this adjective in his dictionary and probably considered both to be correct. He included more possible derivations of this verb in replacements for $\dot{\alpha} \gamma \alpha \pi \dot{\alpha} \zeta \omega$, such as the noun $\tau \dot{o}$

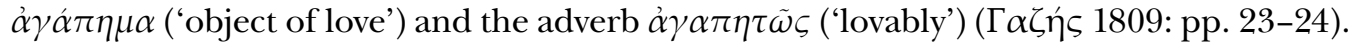

The very detailed analysis of the irregular verb $\dot{\alpha} \varphi \hat{i} v \omega$ ('forsake') is worth mentioning. Korais analysed this word in terms of its grammatical concept. According to Korais, the verb was derived from the particle $\dot{\alpha} \varsigma$, which usually accompanies a verb in the subjunctive. He tried to compare this phenomenon of grammaticalization with the situation in German. He sought similarity in the verb lassen ('leave'), which in its imperative form takes the form lasst, e.g. Lasst uns sehen ('Let us see'). However, he observed a difference in connection with this form of the infinitive. Korais also expanded here on his wellknown proposition about the origin of the Greek future tense form and other grammatical aspects of the verb $\alpha \varphi i v \omega$, but neither Gazis nor Schneider ever even mentioned this verb in their dictionaries.

Both scholars described the verb $\beta \lambda \dot{\varepsilon} \pi \omega$ ('see') in detail. They both included its metaphorical meanings $\kappa \alpha \tau \alpha \lambda \alpha \mu \beta \alpha \dot{v} \omega \omega$ ('understand'), $\pi \rho \circ \sigma \varepsilon \chi \omega \omega$ ('look after'), and $\varphi \rho \circ v \tau i \zeta \omega$ ('take care of'). Gazis did not aim to examine this verb in its all grammatical aspects ( $\Gamma \alpha \zeta \eta$ ' 1809: p. 825). Korais, on the other hand, divided this verb into several morphological categories, as transitive or intransitive, and with a neutral or active voice (Kogańs 1986: pp. 334-339).

Unlike Gazis, Korais did not introduce in his proposed dictionary parts of speech, other than nouns, adjectives, and verbs. He devoted his attention to several of them in other papers relating to phonetics or grammar. 


\section{Beneficial specifics of Korais's and Gazis's lexicographical work}

Apart from individual entries in the form of some parts of speech, Korais devoted considerable attention to proverbs, which he called 'folk philosophy'. In some cases, he spent more time interpreting the oldest Greek sayings than analysing the entry itself. For example, in the entry on the noun $\dot{\eta} \dot{\alpha} \lambda \dot{\eta} \theta \varepsilon \iota \alpha$ ('truth'), he noted several Greek proverbs,

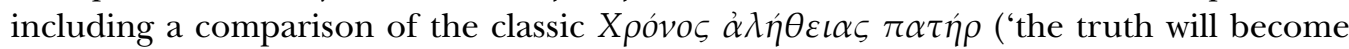

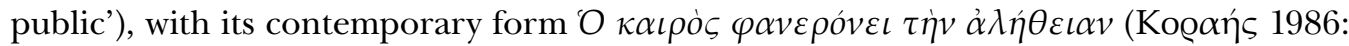
pp. 423-424). Korais intended to correct certain sayings according to his ideal plan. The question is what criteria can now be used to evaluate whether the original or his variant is correct. It is not clear if his point was to make a phrase more precise in its meaning or more representative in its elegance by adding some decorative features (Mackridge 2010: p. 141). Gazis also introduced a few ancient Greek sayings within some entries, but he did so in a very laconic manner.

From a certain perspective, it is possible to appreciate that within the project Korais attempted to create his knowledge of European culture contributed to the emergence of some words that are still preserved in Greek. Frequently cited examples of these lexical

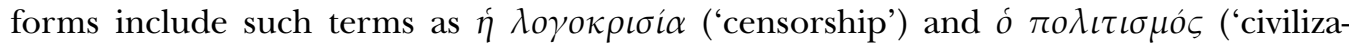
tion'). In this way, he succeeded in linking modern Western notions with classical Greek morphemes (Mackridge 2010: p. 140).

Following this outline, we can infer that Gazis and Korais each conceived of their dictionaries in their own individual way. Although Gazis practically never dealt with morphological or etymological analysis of the entries nor any set phrases, his more natural-scientific approach led to a different contribution to the formation of Modern Greek lexicographical work. For instance, he acquired some of the medical terms in his lexicon, thanks to his good knowledge of classical Greek authors which Korais never even mentioned in his project. To pick some examples at random, there are the nouns

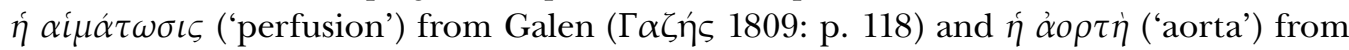

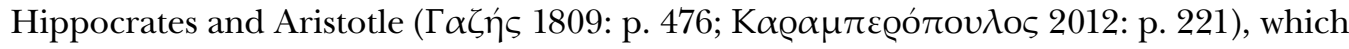

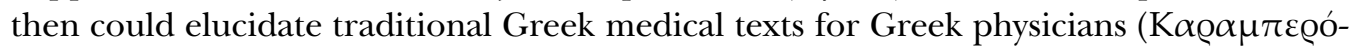

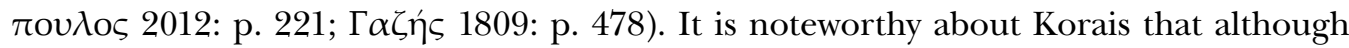
he, unlike Gazis, had had a medical education, he did not pay any special attention to these terms. The reason for this may be that he understood his original profession only as means to ensure his livelihood, not as the centre of his attention, which was undoubtedly classical philology combined with Modern Greek, and consequently also the Greek language question as a social problem (Droulia 2001: p. 249).

\section{Conclusion}

From today's perspective, it might seem that Korais often resorted to a kind of unnecessary word splitting. Upon closer examination of his lexicographical motives, it is possible to understand his deeper intentions. 
It could also be said that etymology became essentially one of the main bases of the Korais's linguistic theory. In his lexicographical work, however, his etymological considerations isolated individual entries rather than giving rise to a general lexical system. Through his research on the origin of words, he created groups of entries and phrases suitable for further analysis rather than a perfectly ordered lexicon ( $\Gamma \varepsilon \omega \varrho \gamma o u ́ \delta \eta \varsigma ~ 1984$ : pp. 66-67).

Gazis, on the other hand, tried to create a dictionary that would not go as deeply into all the spheres of language but would rather be more practically and scientifically oriented, even though the task was obviously more difficult than he had anticipated and resulted in many mistakes along the way.

Nevertheless, if there had been no efforts such as those, made by these two scholars, Greek lexicography would have evolved more slowly than it did.

\section{Bibliography}

Droulia, L. (2001). The classics in the service of renascent Greece: Adamantios Korais and his editorial work. Humanitas, 49, 245-261.

Le Dictionnaire de l'Académie françoise dedié au Roy. (1694). (1 ${ }^{\text {re }}$ éd.). Paris: Jean Baptiste Coignard.

Mackridge, P. (2010). Korais and the Greek language question. In P. M. Kitromilides (Ed.), Adamantios Korais and the European Enlightenment (pp. 127-151). Oxford: Voltaire foundation.

Schneider, J. G. T. (1797). Kritisches griechisch-deutsches Handwörterbuch. Jena - Leipzig: Friedrich Frommann.

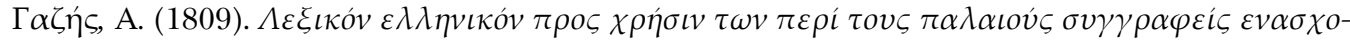

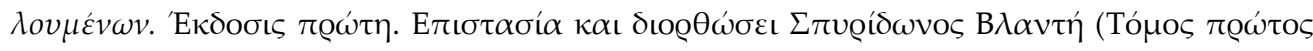

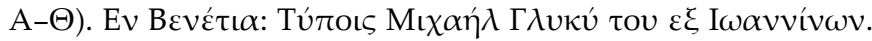

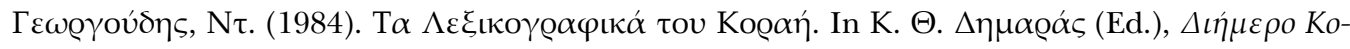

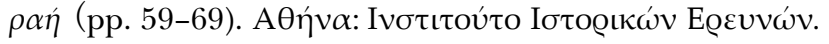

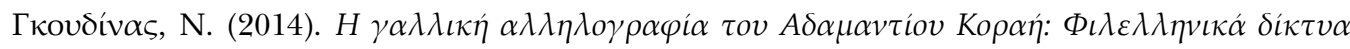

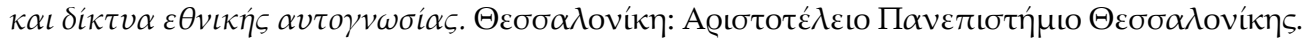

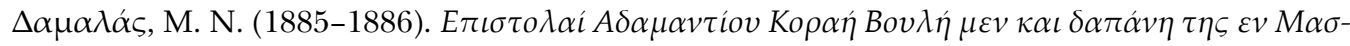

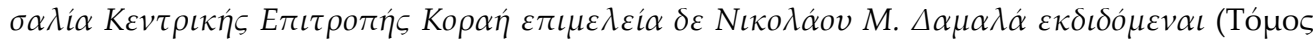

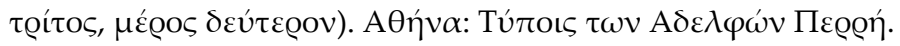

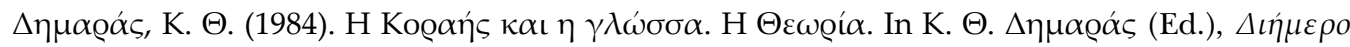

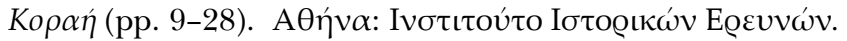

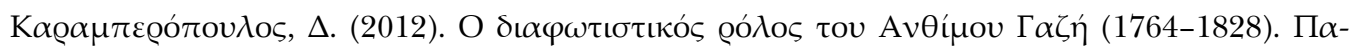

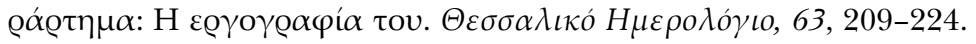

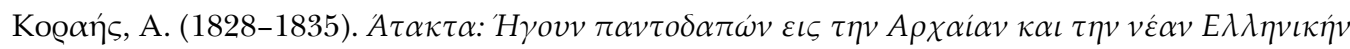

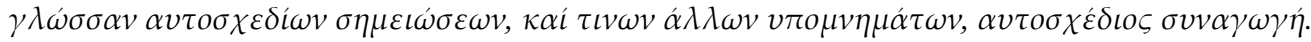

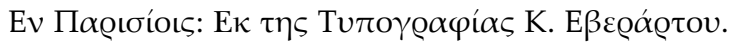

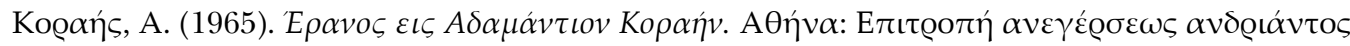

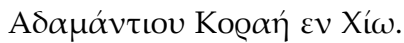




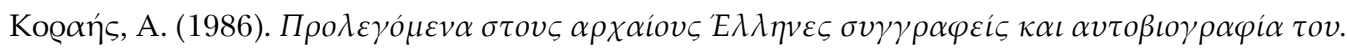

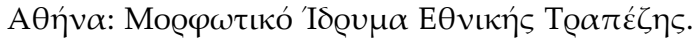

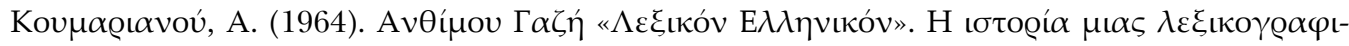

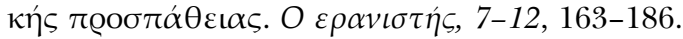

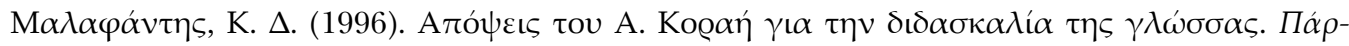
$v \alpha \sigma \sigma o \varsigma, 38,179-190$.

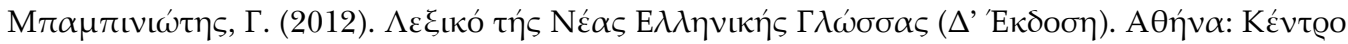
$\Lambda \varepsilon \xi \iota \kappa о \lambda о \gamma i ́ \alpha \varsigma$.

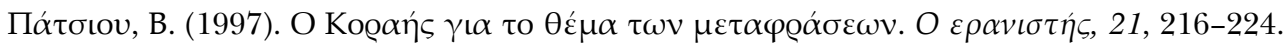

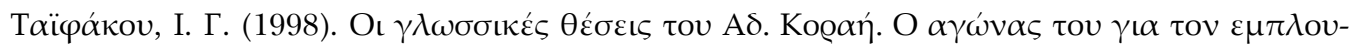

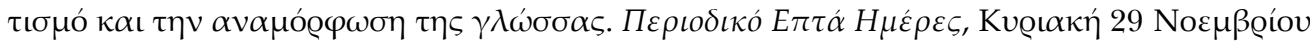
1998, 26-27.

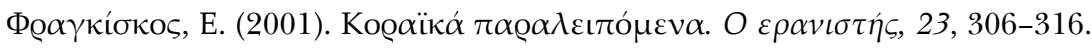

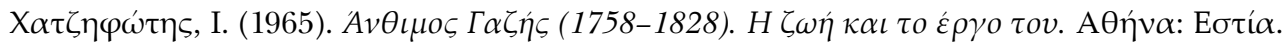

Mgr. Bc. Kristýna Knapková / 264122@mail.muni.cz

Department of Classical Studies

Masaryk University, Faculty of Arts

Arna Nováka 1, 60200 Brno, Czech Republic 